\title{
OECD-Bericht
}

\section{Die Europäer und ihre Gesundheit}

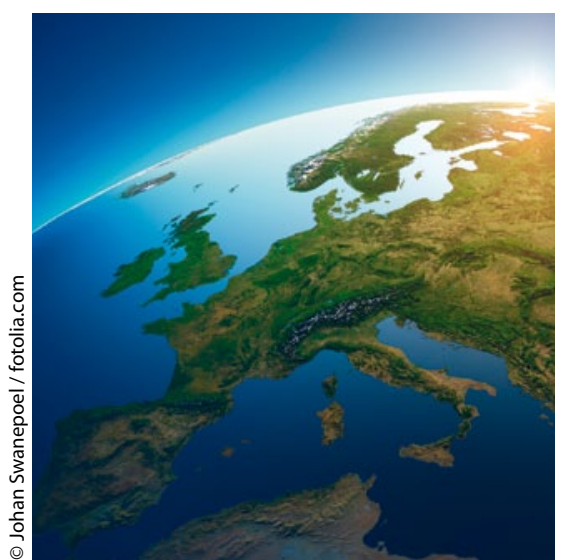

Ein aktueller OECD-Bericht mit Daten aus 35 europäischen Ländern belegt für einige Versorgungsbereiche eine durchaus positive Zwischenbilanz.

- Man wird auf den ersten Blick nicht behaupten können, dass die Länder Europas mit Blick auf die Qualität ihrer Gesundheitsversorgung auf der Stelle treten.

Die Lebenserwartung bei der Geburt ist allein in den Mitgliedsstaaten der Europäischen Union (EU) von 1980 bis 2010 um mehr als sechs Jahre auf 79 Jahre gestiegen. Und der jetzt vorgelegte OECD-Bericht "Health at a glance" mit Daten aus 35 europäischen Ländern zeigt, dass es viele Versorgungsbereiche gibt, in denen die Zwischenbilanz europaweit durchaus positiv ist. Etliche Länder können zum Beispiel beeindruckende Erfolge im Kampf gegen die Gefahren des Tabakkonsums verbuchen. In Island und Schweden liegt der Anteil der Menschen, die täglich rauchen, bei unter 15\% - verglichen mit 30\% im Jahr 1980.

Präventionskampagnen hatten hier offenbar Erfolg, Werbung wurde verboten, Steuern wurden erhöht - das sind echte, beeindruckende Erfolgsgeschichten. Wahr ist aber auch, dass andere Länder hier nicht mitziehen.

In Griechenland etwa konsumieren 30\% der Erwachsenen täglich Tabak. Besorgniserregend ist, dass die Wirtschaftskrise und die wachsenden Haushaltszwänge in vielen europäischen Ländern die nationalen Gesundheitssysteme heftig unter Druck setzen...

Christoph Fuhr 